\title{
BMJ Global Health Polio eradication vaccine investment: how do we ensure polio vaccines are available to keep the world polio-free after transmission of wild poliovirus (wPV) has been interrupted?
}

Amie Batson, ${ }^{1}$ Awi Federgruen, ${ }^{2}$ Nirmal Kumar Ganguly, ${ }^{3,4}$ Amanda Glassman, ${ }^{5}$ Simba Makoni, ${ }^{6}$ Stanley Plotkin ${ }^{7,8}$

To cite: Batson A, Federgruen A, Ganguly NK, et al. Polio eradication vaccine investment: how do we ensure polio vaccines are available to keep the world polio-free after transmission of wild poliovirus (wPV) has been interrupted? BMJ Global Health 2021;6:e006447. doi:10.1136/ bmjgh-2021-006447

Handling editor Seye Abimbola

Received 28 May 2021 Accepted 25 October 2021

Check for updates

(C) Author(s) (or their employer(s)) 2021. Re-use permitted under CC BY-NC. No commercial re-use. See rights and permissions. Published by BMJ.

For numbered affiliations see end of article.

Correspondence to Ms Amie Batson; aebatson@gmail.com

\section{POLIO ERADICATION IS IN SIGHT}

As of 24 August 2021 there has not been a case of wild poliovirus (wPV) anywhere in the world for more than 7 months. Perhaps this is one of the longest periods, if not the longest, without a case of wPV in the world. We may be much closer to polio eradication than any of us had dared hope. If we are, indeed, entering the final stages of polio eradication, planning for post-eradication is essential to keep the world polio-free.

Since the beginning of 2021, there have been only two reported cases of wPV, compared with 102 cases for the same period in 2020 (January to August). There have been 62 wPVpositive environmental samples reported so far this year till August 2021, compared with 304 for the same period in 2020. ${ }^{1}$ There have been no wPV-positive samples from Afghanistan for more than 6 months. ${ }^{2}$ While the polio eradication efforts have made an enormous contribution to COVID-19 control, it may be that the restrictions imposed by the pandemic have brought us this much closer to polio eradication. It is an unexpected synergy. Of course, the reduction in wPV cases in Pakistan may not be sustainable as suggested by Shaikh et $a l,{ }^{3}$ noting their belief that the COVID-19 pandemic may have led to under-reporting in 2020. However, the surveillance networks (including environmental sampling) in both Afghanistan and Pakistan continue to function within the parameters set in the Global Polio Eradication Initiative (GPEI) surveillance indicators.

Some have also noted that the global goal should not focus on just zero cases of wPV, but also on circulating vaccine-derived poliovirus
Summary box

WHO currently recommends that from 2021 onwards every child should receive at least two doses of inactivated poliovirus vaccine (IPV) to prevent any recurrence of wild poliovirus (WPV) or circulating vaccine-derived poliovirus-induced acute flaccid paralysis cases.

- Gavi has forecast that by 2024 as many as 146 million doses of IPV and potentially a further 3 million doses of new IPV-containing hexavalent vaccines could be needed to serve the 70 countries benefiting from its support, globally.

- As of 24 August 2021, there has not been a case of wPV anywhere in the world for more than 7 months and we must start planning for the possibility of eradication much sooner than anticipated.

- The restrictions imposed by the COVID-19 pandemic may finally have brought us this close to eradication.

- There is an urgent need for clearer signals from the global health community on the projected demand for IPV and IPV-containing hexavalent vaccines to ensure that investments in production capacity are made by producers and donors in various regions to assure an adequate and timely supply.

(cVDPV) eradication. Chumakov et al wrote in June 2021 that the strategy of the GPEI had always been based on stopping transmission of wPV, but:

As the circulation of wild polioviruses dwindled, the importance of cVDPVs increased, and they now cause the majority of paralytic polio cases in the world. The distinction between cVDPVs and wild polioviruses is purely academic because they both transmit readily in poorly immunised communities, cause outbreaks of paralytic disease, and their presence requires the same programmatic response. 
As of 24 August 2021, the cumulative cVDPV cases globally were 209 vs 1105 in the entire 2020, and a total of 179 environmental samples were cVDPV-positive compared with 542 in the year $2020 .^{5}$

As we explain below, cVDPV is linked to today's use of live oral poliovirus vaccines (OPV). Alternative polio vaccines reduce the risk, including a novel OPV vaccine that has been granted WHO Emergency Use Listing and may permit control of outbreaks with a much lower risk of further cVDPV cases $^{6}$ and inactivated poliovirus vaccine (IPV).

Three years after the last case of polio caused by wPV, the world will be declared polio-free. After this, polio immunisation will be needed for many more years, both to prevent possible outbreaks of cVDPV and because polioviruses will persist in vitro for many years. ${ }^{7}$ An integral part of the new GPEI Strategy 2022-2026 ${ }^{8}$ involves closer coordination with broader public health efforts, both to prevent recurrence of polio cases and to leverage the polio infrastructure to benefit other public health emergencies long after the disease has been eradicated.

\section{PANDEMIC CHALLENGES}

The COVID-19 pandemic has not only created a global health crisis, but it has also sparked an economic crisis, slowing the global economy ${ }^{9}$ and disproportionately affecting the economies of low-income and lower-middleincome countries. The global economic contraction will undoubtedly negatively impact health spending in highincome and low-income countries, as seen in past recessions. ${ }^{10-12}$ As donor aid budgets are frequently tied to Gross Domestic Product (GDP), international development funds for health are likely to shrink. ${ }^{13}$ This could affect Gavi counterpart financing and the willingness and capacity of some governments to finance their national immunisation programmes.

\section{THE TRANSITION FROM OPV TO IPV}

The WHO polio endgame strategy recommends the cessation of all use of $\mathrm{OPV}^{14}$ and integrating at least two doses of IPV in routine immunisation (RI) programmes once wPV is finally eradicated. As the GPEI explains, 'OPV is very effective against wild poliovirus, but in very rare cases the vaccine can lead to paralysis...', both from vaccine-associated paralytic poliomyelitis and cVDPV, in which mutated versions of OPV can cause paralysis and spread from person to person.

WHO currently recommends that from 2021 onwards every child should receive at least two doses of IPV to prevent any recurrence of $w \mathrm{PV}$ or cVDPV. Gavi and donors have committed to support this introduction in Gavi/GPEI-supported countries. ${ }^{15}$ Children in highincome and some middle-income countries receive four doses of IPV, as two doses of IPV provide $90 \%$ immunity to all three types of poliovirus, while three or more doses provide at least $99 \%$ immunity. ${ }^{16}$ It may, therefore, be that future recommendations are for more than two doses everywhere.

While OPV is inexpensive to produce, it requires a dedicated cold chain $\left(-20^{\circ} \mathrm{C}\right)$, making it expensive to distribute, store and deliver. OPV is often delivered through dedicated and repeated campaigns, requiring significant human resources and often delivering more doses of OPV than necessary over time. In contrast, IPV is more expensive but has the potential to be integrated more fully into the RI system. However, the transition from OPV to IPV will create financial challenges as the savings from stopping OPV will only be realised over time while IPV costs will be immediate.

Some have raised concerns that OPV drops are simpler to administer than IPV injections and that coverage with IPV may, as a result, be lower. There may be countries in which this would be true, but UNICEF/WHO data suggest that it is not in large countries such as Nigeria. Coverage for three doses of OPV (POL3) within an RI system there in 2019 was estimated at about $57 \%$, as was coverage for three doses of injectable Diphtheria-Tetanus-Pertussis (DTP) (DTP3). In India, the figures are 90\% for POL3 and $91 \%$ for DTP3. IPV coverage will depend on the RI programme, and low vaccine coverage rates will need to be addressed through investment in RI.

\section{MEETING POST POLIO ERADICATION DEMAND}

GPEI believes 'the backbone of polio eradication and outbreak response remains RI against polio in line with the national childhood immunisation schedule'. ${ }^{17}$ Gavi has forecast that by 2024 as many as 146 million doses of IPV and potentially a further 3 million doses of new IPVcontaining hexavalent vaccines could be needed to serve the 70 countries benefiting from its support, globally. ${ }^{18}$ In fact, demand for IPV and IPV-containing hexavalent vaccines may be much higher as these Gavi forecasts do not include several large middle-income countries not eligible for its support. Alfaro-Murillo $e t a l^{19}$ concluded in 2020 that 21.1 million doses of IPV would be required annually in just the Americas for a three-dose schedule, and that globally between 232.6 million (for a two-dose schedule) and 348.7 million (for a three-dose schedule) would be needed.

Many countries may choose to accelerate the introduction of IPV-containing hexavalent vaccines because the introduction of pentavalent vaccines, over the last two decades, increased RI vaccine coverage rates, decreased the demand for cold chain capacity and reduced the time per child required of immunisation staff. ${ }^{20}$ Countries may try to replicate these as they balance introducing IPV while also strengthening immunisation programmes in the aftermath of lockdowns and administering COVID-19 vaccines. However, the WHO cautions most countries against switching from whole-cell pertussis $(\mathrm{wP})$ vaccines to the acellular pertussis (aP) vaccines used in highincome countries, ${ }^{21}$ so new IPV-containing wP must be 
developed and approved for those countries currently using wP combinations.

\section{VACCINE SUPPLY CRITICAL FOR A POLIO-FREE WORLD}

Although the production capacity of IPV might be adequate to meet current demand in the short term, an assessment made ${ }^{22}$ of the different vaccine supply scenarios in the post eradication era suggests there is a significant risk of shortages after wPV transmission is interrupted. Shortages of IPV in 2017 and $2018^{23}$ resulted from the long lead times required to scale up IPV production capacity, as it takes roughly 5-7years, from start to finish, to bring a new production facility online. IPV production is complex and must comply with regulatory standards, including stringent biosecurity requirements.

Given the coordinated nature of the global polio eradication effort, the IPV market will be largely determined by global policy and funding decisions. To ensure adequate and quality supply of IPV and IPV-containing hexavalent vaccines to meet global demand, new and existing IPV producers as well as pentavalent producers require clear policy and willingness-to-buy signals from the global health community on the projected global demand for these vaccines in the mid and long term. The robustness and believability of these demand projections will determine if and when production investments are made and whether the world has competitive markets and adequate supply in the future.

\section{CONCLUSION}

The decisions of policymakers today will determine whether or not there will be an adequate supply of IPV and IPV-containing hexavalent vaccines from multiple suppliers around the world to support polio eradication and then to maintain a polio-free world. Robust demand estimates will shape investment in the development of new IPV-containing hexavalent vaccines ${ }^{22}$ and in new and existing production of vaccines that will be needed 5-7 years from now.

A recent $B M J$ feature stated ${ }^{24}$ : 'Since the effort began in 1988 the Global Polio Eradication Initiative has pushed polio to near annihilation, pushing down cases by $99.99 \%$. Perhaps tens of millions of people walking today can thank the GPEI'. We must safeguard this achievement which is at risk from lack of timely and realistic planning.

\footnotetext{
Author affiliations

${ }^{1}$ Global health strategist/expert; Former Chief Strategy Officer and Vice President of Applied Analytics and Learning, PATH, Seattle, Washington DC, USA

${ }^{2}$ Chair of the Decision, Risk, and Operations (DR0) Division, Columbia University \& Graduate School of Business, Columbia University, New York, New York, USA ${ }^{3}$ Honorary Senior Research Professor, Institute of Liver and Biliary Sciences, New Delhi, India

${ }^{4}$ Former Director General, Indian Council of Medical Research (ICMR), New Delhi, India

${ }^{5}$ Executive Vice President \& Senior Fellow, Center for Global Development (CGD), Washington, DC, USA
}

${ }^{6}$ Former Executive Secretary, Southern African Development Community, Gaborone, Botswana

${ }^{7}$ University of Pennsylvania, Philadelphia, Pennsylvania, USA

${ }^{8}$ Wistar Institute, Philadelphia, Pennsylvania, USA

Acknowledgements The commentary is based on the first and second roundtable meetings of RISE - Routine Immunisation to Secure Eradication, in September 2019 and 2020. RISE brings together public health and vaccinology experts as well as economists to explore how best to maintain a polio-free world once eradication is achieved. The authors would like to acknowledge global health writers Jenny Kowalczuk and David Olson.

Contributors All six authors have contributed to conceptualisation and design of the commentary. They have reviewed the literature, data and industry trends available in the public domain, supported by their subject matter knowledge, to frame the narrative of this commentary. All were involved in drafting of the publication, review and revisions. They are all accountable for the accuracy and integrity of this paper.

Funding The RISE round tables were convened by Baird's CMC and supported by Sanofi Pasteur.

Competing interests SP is a consultant to Sanofi Pasteur, a supplier of both IPV and several kinds of OPV.

Patient consent for publication Not required.

Provenance and peer review Not commissioned; externally peer reviewed.

Data availability statement Data are available in a public, open access repository.

Open access This is an open access article distributed in accordance with the Creative Commons Attribution Non Commercial (CC BY-NC 4.0) license, which permits others to distribute, remix, adapt, build upon this work non-commercially, and license their derivative works on different terms, provided the original work is properly cited, appropriate credit is given, any changes made indicated, and the use is non-commercial. See: http://creativecommons.org/licenses/by-nc/4.0/.

\section{REFERENCES}

1 WHO. Global Wild Poliovirus 2016 - 2021, 2021. Available: https:// polioeradication.org/wp-content/uploads/2021/08/weekly-polioanalyses-WPV-20210824.pdf

2 WHO. polioeradication.org, 2021. Global polio eradication initiative. Available: https://polioeradication.org/polio-today/polio-now/ [Accessed 04 Sep 2021].

3 Shaikh N, Fatima N, Muhammad SZ. Poliovirus eradication initiatives in dire Straits: updates from Pakistan. J Glob Health 2021;11:03036 https://jogh.org/poliovirus-eradication-initiatives-in-dire-straitsupdates-from-pakistan/

4 Chumakov K, Ehrenfeld E, Agol VI, et al. Polio eradication at the crossroads. Lancet Glob Health 2021;9:e1172-e1175.

5 WHO. Global Circulating Vaccine-derived Poliovirus (cVDPV), 2021 Available: https://polioeradication.org/wp-content/uploads/2021/08/ weekly-polio-analyses-cVDPV-20210824.pdf

6 WHO. Novel oral polio vaccine type 2 (nOPV2) granted EUL recommendation, 2020. Available: https://polioeradication.org/ news-post/novel-oral-polio-vaccine-type-2-nopv2-granted-interimemergency-use-listing-recommendation/

7 Zimmermann M, Hagedorn B, Lyons H. Projection of costs of polio eradication compared to permanent control. J Infect Dis 2020;221:561-5.

8 GPEI Strategy 2022-2026. Available: https://polioeradication.org/ gpei-strategy-2022-2026/

9 The World Economy: Synchronized Slowdown, Precarious Outlook - IMF Blog [Internet]. [cited 1 Oct 2020]. Available: https://blogs. imf.org/2019/10/15/the-world-economy-synchronized-slowdownprecarious-outlook/

10 Parry J, Humphreys G. Health amid a financial crisis: a complex diagnosis. Bull World Health Organ 2009;87:4-5.

11 Hone T, Mirelman AJ, Rasella D, et al. Effect of economic recession and impact of health and social protection expenditures on adult mortality: a longitudinal analysis of 5565 Brazilian municipalities. Lancet Glob Health 2019;7:e1575-83.

12 Stuckler D, Reeves A, Loopstra R, et al. Austerity and health: the impact in the UK and Europe. Eur J Public Health 2017;27:18-21.

13 "Tough times are ahead": Observers anticipate drop in UK aid budget | Devex [Internet]. [cited 1 Oct 2020]. Available: https://www. 
devex.com/news/tough-times-are-ahead-observers-anticipate-dropin-uk-aid-budget-97090

14 Global Polio Eradication Initiative (GPEI). GPEI polio eradication and endgame strategic plan 2013-2018 and GPEI polio eradication strategy 2022-2026., 2021. Available: https://polioeradication.org/ gpei-strategy-2022-2026/ [Accessed September 4, 2021].

15 Vaccine investment strategy [Internet]. [cited 20 Nov 2020] Available: https://www.gavi.org/our-alliance/strategy/vaccineinvestment-strategy

16 CDC. Polio vaccination: what everyone should know. Available: https://www.cdc.gov/vaccines/vpd/polio/public/index.html

$17 \mathrm{WHO}$. Standard operating procedures responding to a poliovirusevent or outbreak, 2019. Available: https://polioeradication. org/wp-content/uploads/2016/07/sop-polio-outbreak-responseversion-20193101.pdf

18 GAVI. Base Demand Forecast "v17" prepared 2019. [cited 12 Jun 2020], 2019. Available: https://www.gavi.org/sites/default/files/
document/supply-procurement/Base-Demand-Forecast-v17-PublicSummary.pdf

19 Alfaro-Murillo JA, Ávila-Agüero ML, Fitzpatrick MC, et al. The case for replacing live oral polio vaccine with inactivated vaccine in the Americas. Lancet 2020;395:1163-6.

20 Pentavalent vaccine support [Internet]. [cited 26 Sep 2020]. Available: https://www.gavi.org/types-support/vaccine-support/ pentavalent

21 WHO. Pertussis vaccines: WHO position paper - August 2015. Geneva: WHO, 2010. https://apps.who.int/iris/bitstream/handle/ 10665/242413/WER9035_433-458.PDF?sequence $=1$

22 RISE (Routine Immunisation to Secure Eradication). 2020. Scenario assessment undertaken by RISE.

23 Sutter RW, Cochi SL. Inactivated poliovirus vaccine supply shortage: is there light at the end of the tunnel? J Infect Dis 2019;220:1545-6.

24 Fortner R. Has the billion dollar crusade to eradicate polio come to an end? BMJ 2021;374:n1818. 